TM-1595

[SSC-N-637]

\title{
SSC Superconducting Dipole Magnet Cryostat \\ Magnet Cryostat Model Style B Construction Experience*
}

\author{
N. H. Engler, R. C. Bossert, J. A. Carson, J. D. Gonczy, \\ E. T. Larson, T. H. Nicol, R. C. Niemann, D. Sorenson, and R. Zink \\ Fermi National Accelerator Laboratory \\ P.O. Box 500, Batavia, Illinois
}

March 1989

* Manuscript prepared for the 1989 International Industrial Symposium on the Super Collider (IISSC), New Orleans, Louisiana, February 8-10, 1989. 
SSC SUPERCONDUCTING DIPOLE MAGNET CRYOSTAT MAGNET CRYOSTAT MODEL STYLE B CONSTRUCTION EXPERIENCE

\author{
N.H. Engler, R.C. Bossert, J.A. Carson, J.D. Gonczy \\ E.T. Larson, T.H. Nicol, R.C. Niemann, D.Sorenson, R.Zink \\ Fermi National Accelerator Laboratory \\ Batavia, Illinois 80510
}

\title{
ABSTRACT
}

A program to upgrade the full scale SSC dipole magnet cryostat model function and assembly methods has resulted in a series of dipole magnets designated as style $B$ construction. New design features and assembly techniques have produced a magnet and cryostat assembly that is the basis for Phase I of the SSC dipole magnet industrialization program. Details of the assembly program, assembly experience, and comparison to previous assembly experiences are presented. Improvements in magnet assembly techniques are also evaluated.

\section{INTRODUCTION}

The SSC dipole magnet development program includes the assembly of a premanufactured coil and cold mass sub-assembly built at Brookhaven National Laboratory into a cryostat system that was manufactured at Fermilab. ${ }^{1}$

The concept of different manufacturers each building a major component of the magnet which could be assembled at any site is one of the goals of the program.

A full scale dipole magnet designated model $A$ was manufactured and assembled as a second step in the development of the final design. ${ }^{2}$

The complete magnet contains all of the magnet support systems, anchor system, thermal isolation shield, insulation, expansion joints, vacuum vessel, magnet interconnection devices, and a complete alignment system.

\section{COMPLETE MAGNET}

The complete magnet has been previously described in detail ${ }^{3}$ and only its major features are presented herein. The magnet general arrangement is as shown by Fig. 1. and Fig. 2.

Cold Mass Assembly

The cold mass assembly consists of the beam tube, correction elements, collared coils, laminated iron yoke, and outer helium containment shell. The cold mass components are joined together forming a leak tight and structurally rigid assembly. 

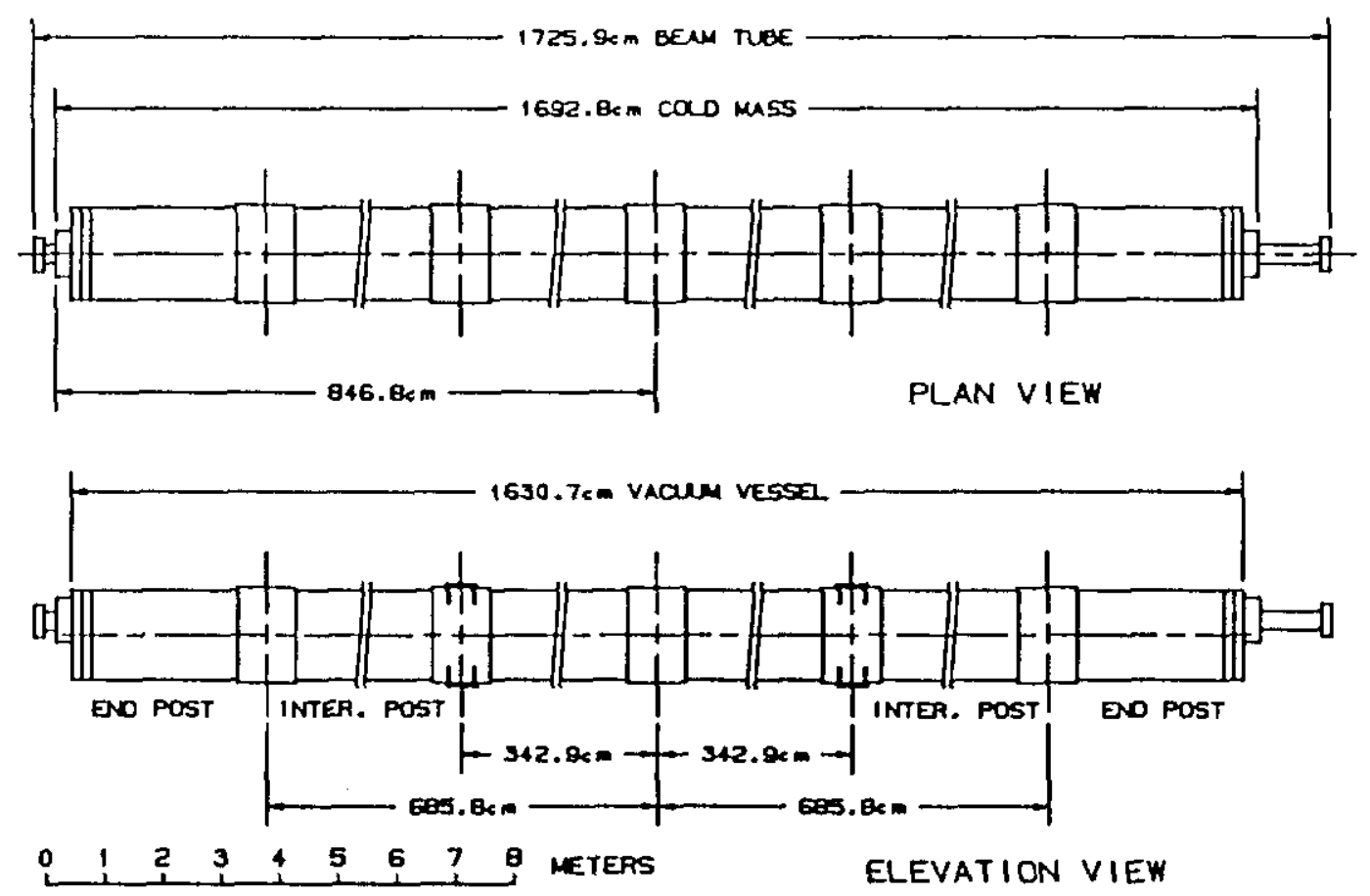

Fig. 1. Cryostat plan and elevation views.

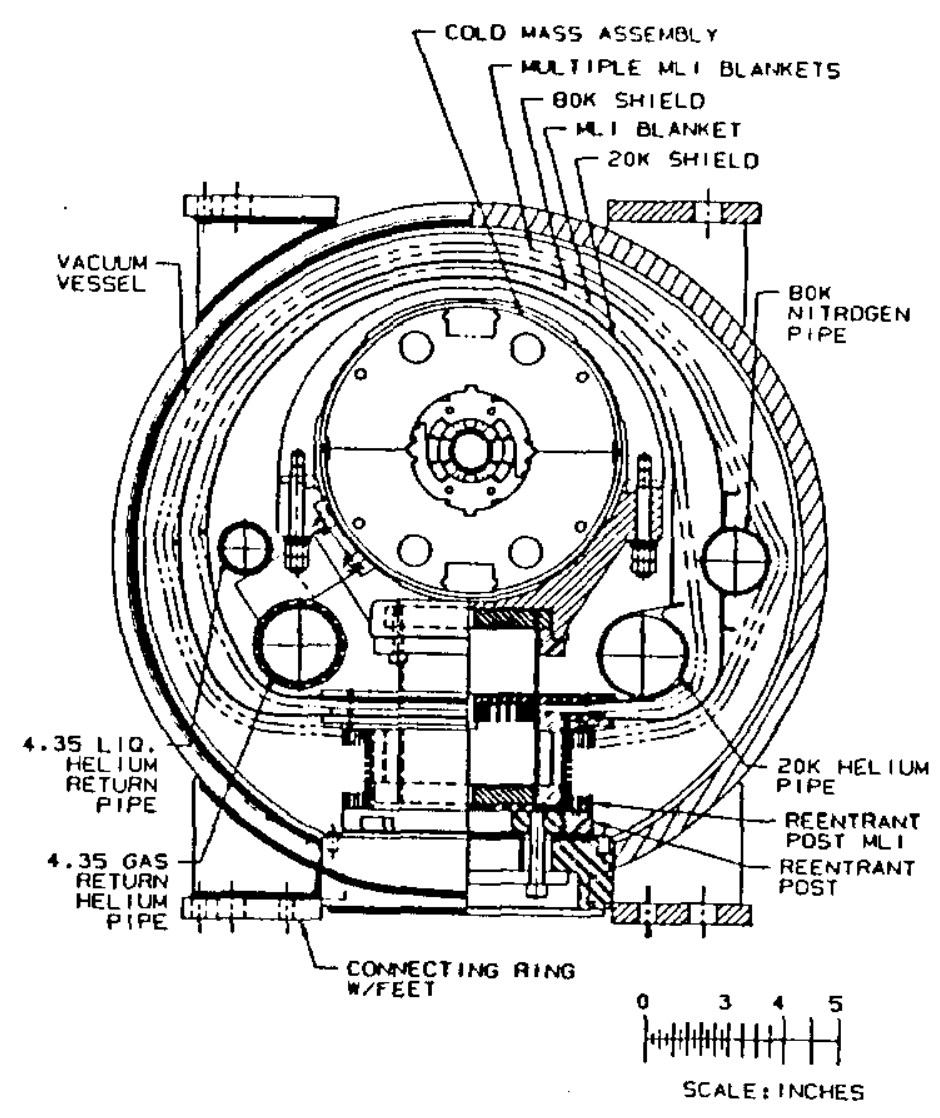

Fig. 2. Cross Section through a support point. 


\section{Cryogenic Piping}

The cryostat assembly contains all piping that interconnects the magnet refrigeration system throughout the circumference of the accelerator rings. A five pipe system is employed for cryogenic and safety reasons.

Thermal Shields

Thermal shields maintained independently at $20 \mathrm{~K}$ and $80 \mathrm{~K}$ surround the cold mass assembly. The shields absorb the radiant heat flux and provide heat sink stations for the suspension and anchor system. The shields are supported by and thermally connected to the cold mass assembly supports.

Insulation

The insulation system consists of multi-layer assemblies of aluminized polymer film with spacers fabricated and installed as blankets on the cold surfaces. ${ }^{4}$ One blanket is installed on the cold mass circumference, two blankets are installed on the $20 \mathrm{~K}$ shield, and four blankets are installed on the outer 80 $\mathrm{K}$ shield.

\section{Suspension System}

The cold mass and shields are supported relative to the vacuum vessel at five points by the suspension system. ${ }^{5}$ The system incorporates a reentrant type support post. The outer tube is manufactured from a fiberglass reinforced epoxy composite. The inner tube is manufactured from a graphite reinforced epoxy composite. The support system also includes attached metalic and connections and heat intercepts that connect to the thermal shields.

\section{Anchor System}

The five support posts share vertical and lateral loads. The center post is rigidly attached to the cold mass to establish axial position.

\section{Vacuum Vessel}

The vacuum vessel provides containment for insulating vacuum and the cold mass connection to ground. The magnet assembly procedure incorporates insertion of the complete subassembly into the vacuum vessel.

\section{Interconnections}

Mechanical and electrical interconnections between adjacent magnets are required at the magnet ends. ${ }^{6}$ It is essential that the connections be straight forward to assemble and disassemble, compact, and reliable. The design facilitates assembly and disassembly operations in the SSC tunnel.

\section{ASSEMBLY}

The major components of the dipole cryostat, i.e., the magnet proper in its helium containment vessel(cold mass), cryogenic piping, heat shields and insulation are located and supported by reentrant posts connected to the tow plate. This major subassembly, complete with the anchor system and heat intercepts, is inserted into an outer vacuum vessel. 
As a first step in final magnet assembly, the pre-manufactured magnet cold mass is located on an assembly station, and slide cradles with their supporting subassembly, are installed. Next the five assembled support posts are installed with the cold mass supported on a locating fixture. The anchor system is installed from the center position outward in two directions interconnecting the five support posts. A single blanket of insulation material is installed around the circumference of the cold mass. After final installation of the helium return piping, the lower half of the $20 \mathrm{~K}$ shield is installed and attached to the support system. Thermal insulation blankets are installed on the $20 \mathrm{~K}$ heat shield and heat conductive straps are connected to the shield. The upper half of the $20 \mathrm{~K}$ shield is installed and the insulation is completed. The same procedure follows for the installation of the $80 \mathrm{~K}$ shield. These steps are completed on a fixtured table that contains the cold mass slide that positions and maintains the integrety of the cold mass subassembly prior to insertion into the vacuum vessel. The arrangement is as shown in Eig. 3.

\section{Vacuum Vessel}

The vacuum vessel is fabricated from prefabricated, full section reinforcing rings connected by short sections of tubing. Two of the five support rings have external magnet mounting feet attached to them. The five support positions are mounted on a vacuum vessel assembly fixture which controls the position of the rings. Short links of tubing are used to interconnect and fix the relative ring positions. The machined surfaces of the feet are perpendicular and parallel to related surfaces of the support posts. This arrangement assures alignment of the center of the beam tube in the cold mass with respect to the outside of the vacuum vessel. End rings to support vacuum bellows and automatic welding equipment are then welded to the vessel to complete the assembly. The inspected assembly is then transferred to the final assembly station where the alignment and support tray is installed. A cross section through a support point is shown in Fig. 4.

\section{Final Assembly}

The cold mass subassembly and vacuum vessel are lined up, and a slide and pulley system draws the cold mass subassembly into the vacuum vessel. Fig. 5. Precision fixture points, together with the positive location of the support post feet, allow the cold mass to be located properly relative to the vacuum vessel. The assembly is then clamped and welded together as a unit. An optical survey is taken to assure the correct alignment of all components. The vessel is then inspected, given a final leak check, painted and prepared for protection from the weather. The assembly is now ready for shipment to the testing and measuring operations. 

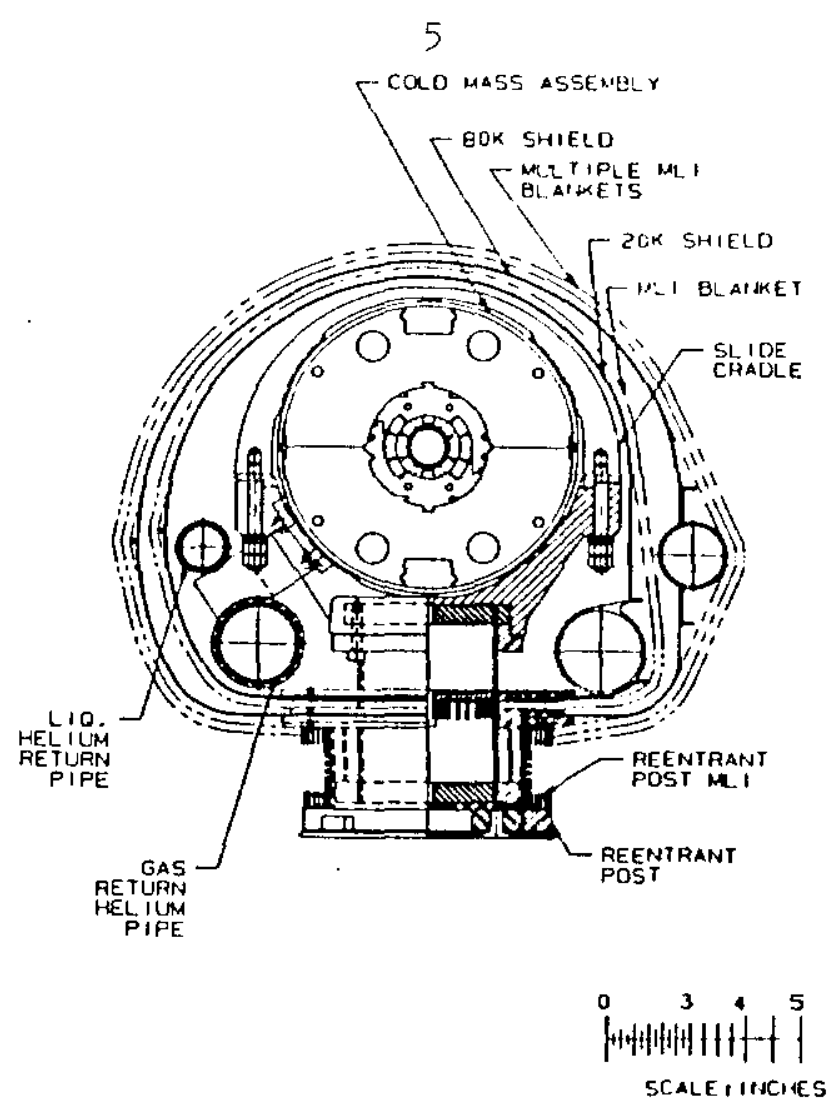

Fig. 3. Cold mass assembly.

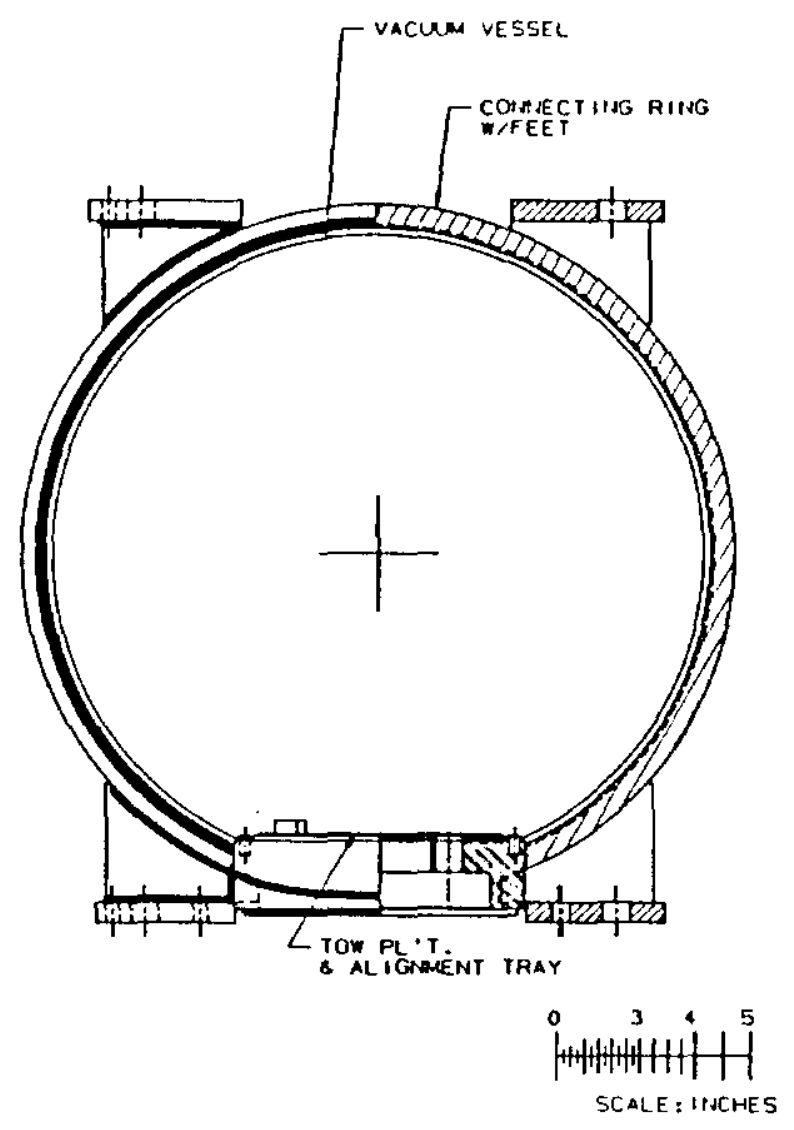

Fig. 4. Vacuum vessel subassembly. 


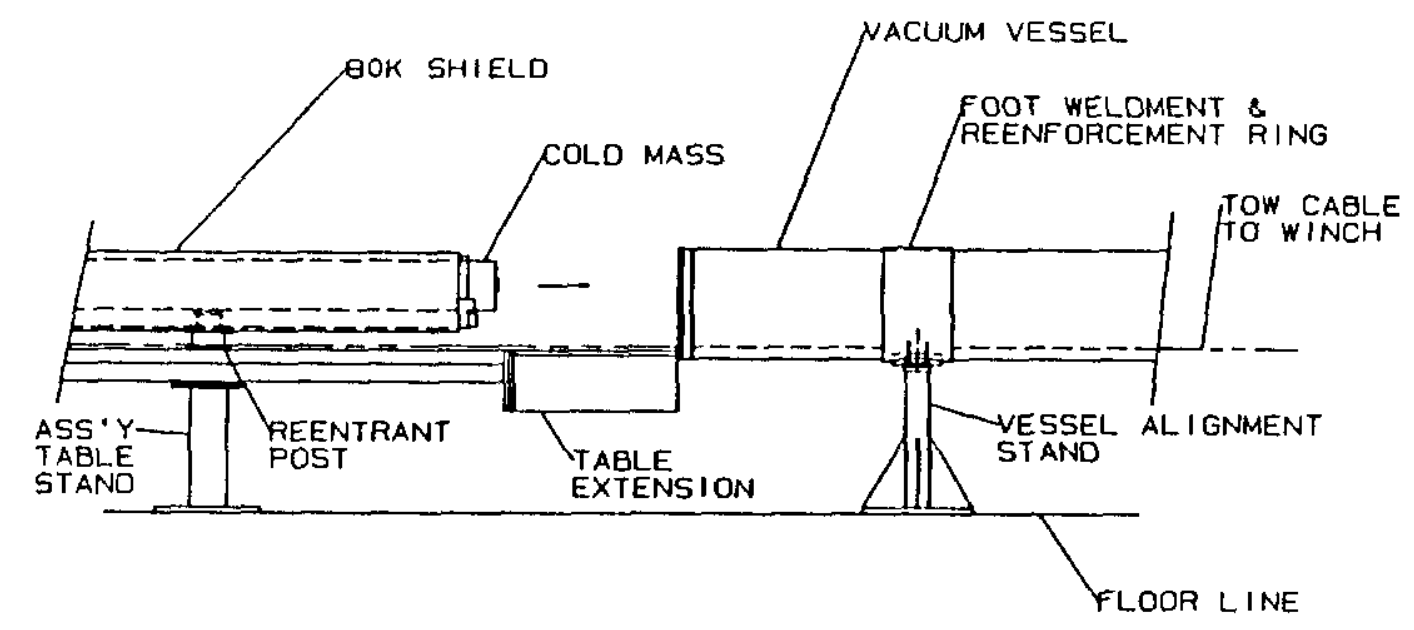

Fig. 5. Magnet final assembly fixture.

\section{Factory Certification Tests}

The tests required to certify each dipole for SSC acceptance, before it leaves the factory or factories, include several types and are performed at various stages of the fabrication and assembly process. These tests, conducted at room temperature, are summarized.

(a) Electrical Measurements and Tests

1. Resistance, inductance of each of the four windings and of the complete magnet.

2. Hi-pot between windings, between windings and collars, and between coil and bore tubes to $2-3 \mathrm{kV}$.

(b) Magnetic Measurements

All magnets will have field measurements made at room temperatures. The current will be limited to $+15 \mathrm{~A}$, and the following quantities will be measured:

$B_{0}, a_{n}$, and $b_{n} n=1$ to 6 .

The field at $15 \mathrm{~A}$ is about $150 \mathrm{G}$.

\section{RESULTS}

The completion of the Type A cryostats gave us vaulable experience to improve the assembly operation in the style $B$ magnet assemblies. Improved assembly fistures, tooling, and measurement techniques assured a consistent magnet assembly that would duplicate itself with subsequent magnets. Specific improvements were noted in the following areas. 


\section{Cold Mass Subassembly}

Cold mass assemblies were received from Brookhaven National Laboratory that had a consistent o.d. and surface finish that allowed a new slide support system to be incorporated. The new anchor system eliminated many holes cut into the thermal shields and assisted in the application of insulation on the shields. New helium piping supports were designed that permitted installation of tubing as a completed subassembly. The $20 \mathrm{~K}$ and $80 \mathrm{~K}$ heat shields were reconfigured to allow easier assembly and easier connection to the thermal intercepts. The ability to incorporate automatic spot welding of shields allowed for less distortion and interferences of the total assembly. The insulation blankets were made on a production style assembly fixture that gave us consistent, repeatable blankets that fit with the minimum of hand fitting on the magnet itself.

Vacuum Vessel

The new tooling that aligned the five support points and two mounting feet together with design modifications that allowed the use of automatic welding equipment greatly reduced the effort required to furnish an accurate vacuum vessel. Assembly techniques of the support rings, slide plate, and slide trays provided for the alignment of the cold mass subassembly with a minimum of special handling.

\section{Alignment Reference}

The new assembly system allowed the technicians to use the inside of the bore tube to verify the integrety of the magnet. Survey techniques were developed and improved to assure that the cold mass was in the proper relation to the mounting feet and support rings in the vacuum vessel.

\section{IMPROVEMENTS}

All of the systems will benefit from ongoing tooling and fixture upgrades. Redesign of parts for increased operating clearances, welding equipment clearances, and final assembly clearances will become part of the design $C$ iteration and will result in an improved assembly process.

\section{CONCLUSIONS}

The design $\mathrm{B}$ magnet is functional and produces a satisfactory SSC dipole assembly. Automatic welding is a major time saver and must be used wherever possible. The magnet is of a satisfactory quality to allow the Phase I industrialization program to go forward.

\section{Acknowledgements}

The authors gratefully acknowledge the sincere interest, contribution, cooperation, and professional performance of the Fermilab design, production, procurement, quality assurance, and engineering test groups.

These efforts resulted in an assembled SSC dipole magnet that proved many new principles of design and assembly techniques. The work was completed on schedule, and ddelivered to the Fermilab magnet test facility for further evaluation. 
The work as presented was performed at Fermilab National Accelerator Laboratory which is operated by Universities Research Association, Inc. under contract with the U. S. Department of Energy.

\section{REFERENCES}

1. SSC Central Design Group, "Conceptual Design of the Superconducting Super Collider," SSC-SR-2020, March, 1986.

2. Engler, N.H.,et al, "SSC Dipole Magnet Model Construction Experience," presented at the 1987 Cryogenic Engineering Conference, June 14-18, 1987, St. Charles, Illinois.

3. R.C. Niemann, et al, "Second Generation Superconducting Super Collider Dipole Magnet Cryostat Design," Annual Energy Souces Technology Conference, January 23-25, 1989 in Houston, Texas.

4. Ohmori, T., et al, "Thermal Performance of a Candidate SSC Magnet Thermal Insulation Systems," Adv. Cryo. Engr. Vol. 33, pp 323,(1987)

5. Nicol, T.H., et al., "SSC Magnet Cryostat Suspension System Design," Adv. Cryo. Engr., Vol. 33, pp 227, (1987).

6. R.A. Bossert, et al, "Superconducting Magnet Interconnections," International Industrial Symposium On The Super Collider Conference February 8-10, 1989, in New Orleans, Louisiana. 